\title{
CDNA Subtraction
}

National Cancer Institute

\section{Source}

National Cancer Institute. cDNA Subtraction. NCI Thesaurus. Code C18686.

A difference cloning method and a technique for comparison of two closely related cell types, e.g. a differentiated or transformed cell (tester) and the undifferentiated or normal cell (driver). Driver RNA is converted to double-strand CDNA, usually with the incorporation of a tagged nucleotide, while the tester RNA is converted to first-strand cDNA (with no tag). The two preparations are mixed, melted and annealed to form, among other species, heteroduplexes composed of one strand from each of the different sources. The annealed heteroduplexes, as well as other driver species are captured by the tagged nucleotide and removed from the mixture. The resulting pool will be enriched for those cDNA species unique to the tester cells. Following second-strand synthesis, the double-stranded cDNAs are cloned. The resulting CDNA library will be enriched for sequences expressed only in the tester cells. cDNA subtraction can also be done by PCR. (NCI/OSP) 